Original Article

\title{
Effects of cane use on walking parameters and lower limb muscle activity in adults with spastic cerebral palsy: a cross-sectional study
}

Takahito Inoue, RPT, MSc ${ }^{1)^{*}}$, Yui Sato, RPT, $\mathrm{MSc}^{2)}$, Kotaro Shimizu, RPT, PhD ${ }^{3)}$, Hideyuki TAShiro, RPT, PhD ${ }^{2}$, Yuichiro Yokol, RPT, PhD ${ }^{4}$, NAOKI KozuKa, RPT, PhD ${ }^{2}$

1) Division of Rehabilitation Medicine, Hokkaido Medical Center for Child Health and Rehabilitation: 1240-6 Kanayama 1, Teine-ku, Sapporo, Hokkaido 006-0041, Japan

2) Department of Physical Therapy, Graduate School of Health Science, Sapporo Medical University, Japan

3) Department of Rehabilitation for the Movement Functions, Research Institute of National Rehabilitation Center for the Disabled, Japan

4) Department of Physical Therapy, Faculty of Human Science, Hokkaido Bunkyo University, Japan

\begin{abstract}
Purpose] Adults with cerebral palsy often use a cane as a walking aid because of their decreased gait ability. However, it is unclear whether this affects lower limb muscle activity during walking. The purpose of this study was to clarify the influence of using a cane during walking on the spatio-temporal parameters of walking, lower limb muscle activity, and lower limb muscle coactivation in adults with spastic cerebral palsy. [Participants and Methods] Eleven participants with cerebral palsy were included. The spatio-temporal parameters of walking, lower limb muscle activity, and coactivation of lower limb muscle were measured during a $10 \mathrm{~m}$ trial with no cane, one cane, and two canes. [Results] Walking speed was lower and the stride time longer when using two canes than when using no cane. All muscle activities significantly reduced when using two canes. No significant difference was observed between using no cane and one cane, except for walking speed. In addition, there was no significant difference in coactivation between the conditions. [Conclusion] This study revealed that when two canes were used, the walking speed was reduced, and lower limb muscle activity was reduced, reducing the burden. In contrast, the movement pattern was not suggested to have changed. Key words: Cerebral palsy, Cane, Electromyography
\end{abstract}

(This article was submitted Mar. 15, 2021, and was accepted Apr. 19, 2021)

\section{INTRODUCTION}

Walking ability in cerebral palsy $(\mathrm{CP})$ is associated with activities of daily living and quality of life (QOL) ${ }^{1,2)}$. It has been reported that walking ability may decline or be lost in adults with $\mathrm{CP}^{3)}$, who may require a walking aid such as a cane. Logan et al. $\left.{ }^{4}\right)$ report that walking aids improve mobility if used correctly.

There are several benefits of using a cane ${ }^{5-8)}$. A cane may enhance stability ${ }^{6}$, reducing weight-bearing on the lower limb, and reduce the vertical ground reaction force ${ }^{5}$. Moreover, a cane is useful, not only for biomechanical stability, but also for control of balance by the central nervous system (CNS) by providing sensory input ${ }^{7)}$. Yeung et al. ${ }^{8)}$ reported a decrease in walking speed and cadence, and increase in stride time when using a cane in spastic CP children; it was suggested that muscle activity in the lumbar region was reduced when using a cane, leading to prevention of pain ${ }^{8)}$. Thus, using a cane may change the walking parameters and muscle activity of adults with CP. However, there is insufficient evidence because there are few

*Corresponding author. Takahito Inoue (E-mail: takahito.inoue1@gmail.com)

(C2021 The Society of Physical Therapy Science. Published by IPEC Inc.

(c) (1) $\odot$ This is an open-access article distributed under the terms of the Creative Commons Attribution Non-Commercial No DerivacC. 
studies regarding the use of canes within this population.

The activity pattern of coactivation is well-documented in $\mathrm{CP}$ and reported to be detrimental to motor performance ${ }^{9)}$. Patients with CP have an impaired CNS, and inadequate control of lower limb muscle activity ${ }^{10,11}$. In addition, CP patients exhibit unstable walking because of declined balance ability. In an unstable situation, as postural control is compensated through the coactivation of agonist and antagonist muscles, the rate of coactivation increases ${ }^{12}$. In a study of healthy adults comparing postural sway and coactivation of the ankle joint muscles, coactivation was reduced and postural sway was decreased when lightly gripping a cane in standing ${ }^{13}$. In stroke patients, it has been reported that coactivation of the ankle joint muscles during walking decreased after balance training ${ }^{14)}$. Thus, the contribution of stability by the sensory input and increased base of support when using a cane may reduce coactivation of the lower limbs while walking. However, the effect of using a cane on lower limb muscle activity on walking in CP remains unclear. Reduced coactivation may allow for more diverse postural control ${ }^{15}$ because excessive muscle coactivation causes high joint stiffness and reduces free postural control.

The purpose of this study was to clarify the effect of using a walking cane in adults with spastic $\mathrm{CP}$ on walking parameters, lower limb muscle activity, and lower limb muscle coactivation. We hypothesized that walking speed and cadence would decrease, and stride time would increase when using a cane, as reported in previous studies ${ }^{8}$. Furthermore, we hypothesized that muscle activity and coactivation in the lower limbs would be reduced when using a cane.

\section{PARTICIPANTS AND METHODS}

Eleven community-dwelling participants with CP (mean age, $28.0 \pm 10.3$ years; Gross Motor Function Classification System (GMFCS) classes: I, three participants; II, five participants; III, three participants) participated in this study. The inclusion criteria were as follows: (1) age over 18 years; (2) diagnosis of spastic CP; (3) ability to walk independently without an assistive device for at least $10 \mathrm{~m}$; and (4) ability to follow simple instructions. The exclusion criteria were as follows: (1) orthopedic surgery within the previous 6 months; and (2) botulinum toxin injections to the lower extremities within the previous 3 months. This study was a cross-sectional design. Measurement of research data was conducted at Sapporo Medical University from November to December 2017. All procedures were approved by the ethics committee of Sapporo Medical University and all participants provided written informed consent before starting this study (Authorization Number: 29-2-11).

We used a general T-cane $(0.35 \mathrm{~kg})$ and adjusted the length of the cane before data measurement. The length of the cane was adjusted such that the grip was at the level of the femoral greater trochanter when the cane was placed $150 \mathrm{~mm}$ obliquely forward from the apex of the foot. When participants used one cane, the cane was held with the easy-to-use hand; when participants used two canes, each cane was held in a hand. For two canes, four-point reciprocal gait (right hand/left foot and vice versa) training was performed before data acquisition. Training was for 3 round trips on a $10 \mathrm{~m}$ walkway.

All participants performed $10 \mathrm{~m}$ walking tests at a comfortable walking speed with bare feet. A $16 \mathrm{~m}$ walkway was used, with a $3 \mathrm{~m}$ area for acceleration and deceleration. Each subject was assessed under the following three conditions in randomized order: (1) walking unaided (no cane); (2) walking with one cane; and (3) walking with two canes. Each condition was tested twice. We measured the number of steps and walking time.

Electromyography (EMG) signals were recorded during the $10 \mathrm{~m}$ walking tests using a Trigno Wireless System (Delsys Inc., Boston, MA, USA) at a sampling rate of 2,000 Hz. The sensor has a built-in accelerometer as well as an electromyogram and collects data simultaneously. Skin abrasion and alcohol cleaning were conducted before electrode attachment to reduce impedance. The target muscle groups included the rectus femoris (RF), biceps femoris (BF), tibialis anterior (TA), and gastrocnemius lateral head (GL); measurement was performed with the lower limb of one side under all three conditions, and the measuring side was the lower limb on the opposite side of the cane when using one cane. The electrodes were placed in reference to the contents of the SENIAM project (http://www.seniam.org). In addition, one electrode was attached to the heel for assessing one walking cycle from acceleration. One walking cycle was detected from the foot strike and foot-off events of each walking test ${ }^{16)}$.

The number of steps and walking time were averaged from the two trials. Walking speed, stride length, stride time, and cadence were calculated from the average number of steps and walking time.

Raw EMG signals were band-pass filtered at $20-450 \mathrm{~Hz}$ before data analysis. The magnitude of muscle activity was calculated as the root mean square (RMS) of the electromyographic signal for each muscle, EMG amplitudes were normalized by the average amplitude of each muscle over the entire gait cycle, and by averaging five gait cycles. The magnitude of agonist and antagonist muscle coactivation was calculated using the co-activation index $(\mathrm{CoI})$ according to previous studies ${ }^{17}$, 18). The band-pass-filtered EMG signals were full-wave rectified and were time normalized to $100 \%$ in the gait cycle. Each muscle EMG parameter was calculated from five gait cycles and normalized by the average amplitude of the muscle over the entire gait cycle. The CoI was calculated by the overlap duration of the agonist-antagonist divided by the number of data points, as per previous studies ${ }^{17,18)}$. In addition, CoI was calculated for the thigh and leg during the stance (St) and swing (Sw) phases.

The normality of all data was confirmed using the Shapiro-Wilk test. Then, repeated-measures analysis of variance (ANOVA) and post hoc Tukey tests were used to assess differences between walking parameters or muscle activity between each condition. All data analyses were performed using SPSS software version 21.0 for Windows (IBM Corp., Armonk, NY, USA). Statistical significance was set at a p value $<0.05$. 


\section{RESULTS}

The demographic data of the participants are shown in Table 1. Three participants used a cane, and eight participants did not use the cane in daily life.

Table 2 shows the results of different walking parameters, each muscle RMS, and CoI under each condition. Repeatedmeasures ANOVA showed a significant difference in the number of canes for walking speed and stride time (walking speed: $\mathrm{F}_{1.183,11.826}=10.599, \mathrm{p}=0.005$; stride time: $\left.\mathrm{F}_{1.139,11.390}=10.711, \mathrm{p}=0.006\right)$. As a result of post hoc Tukey tests, there was a significant difference in walking speed and stride time between two canes and without a cane (walking speed: $p=0.001$; stride time: $\mathrm{p}=0.001$ ).

Also, repeated-measures ANOVA showed a significant difference in the number of canes for all muscles (RF: $F_{1.215}$, ${ }_{12.151}=8.735, \mathrm{p}=0.009 ; \mathrm{BF}: \mathrm{F}_{1.146,11.459}=3.593, \mathrm{p}=0.080 ; \mathrm{TA}: \mathrm{F}_{1.106,11.063}=6.704, \mathrm{p}=0.023 ; \mathrm{GL}: \mathrm{F}_{1.33,13.329}=7.894, \mathrm{p}=0.010$ ). As a result of post hoc Tukey tests, there was a significant difference in all muscles between two canes and without a cane (RF: $p=0.001$; BF: $p=0.039$; TA: $p=0.004$; GL: $p=0.002$ ). However, there were no significant differences between without a cane and with one cane and between with one cane and with two canes for all muscles. Also, Table 2 show the results of the difference of $\mathrm{CoI}$ under each condition. There was no significant difference in CoI among all the conditions.

Table 1. Demographic data and walking speed of the participants

\begin{tabular}{cccclccc}
\hline & & & & & \multicolumn{3}{c}{ Walking speed (m/min) } \\
\hline Participant & Age & Gender & GMFCS & Use of the cane in daily life & No cane & One cane & Two canes \\
\hline 1 & 31 & Male & III & Two canes & $58.5(6.0)$ & $56.4(0.7)$ & $59.1(0.1)$ \\
2 & 32 & Male & II & One cane (winter only) & $63.5(0.2)$ & $57.3(6.0)$ & $54.1(2.2)$ \\
3 & 47 & Female & II & Unused & $51.3(0.3)$ & $43.3(1.3)$ & $38.6(1.6)$ \\
4 & 27 & Male & II & Unused & $75.1(0.9)$ & $69.6(7.9)$ & $68.9(4.3)$ \\
5 & 21 & Female & II & Unused & $60.5(4.6)$ & $41.3(1.9)$ & $32.5(2.9)$ \\
6 & 45 & Female & III & One cane & $39.2(0.9)$ & $44.6(0.5)$ & $46.2(0.3)$ \\
7 & 18 & Male & I & Unused & $79.8(3.0)$ & $74.7(4.9)$ & $74.0(3.4)$ \\
8 & 18 & Female & I & Unused & $81.7(1.3)$ & $76.0(8.4)$ & $68.4(4.1)$ \\
9 & 29 & Male & III & Two canes & $25.9(2.4)$ & $27.4(2.0)$ & $31.4(1.4)$ \\
10 & 21 & Male & I & Unused & $69.1(6.5)$ & $67.3(2.4)$ & $65.9(0.67)$ \\
11 & 19 & Female & II & One cane (winter only) & $49.5(0.1)$ & $39.1(0.3)$ & $37.6(1.3)$ \\
\hline
\end{tabular}

Data are presented as mean (SD).

GMFCS: Gross motor function classification system.

Table 2. Results of walking parameters and muscle activity

\begin{tabular}{lccc}
\hline & \multicolumn{3}{c}{ Condition } \\
\cline { 2 - 4 } & No cane & One cane & Two canes \\
\hline Walking speed $(\mathrm{m} / \mathrm{min})$ & $59.9(18.0)$ & $54.3(16.3) *$ & $52.0(16.2)^{*}$ \\
Stride length $(\mathrm{m})$ & $0.8(0.2)$ & $0.8(0.2)$ & $0.8(0.2)$ \\
Stride time $(\mathrm{s})$ & $0.86(0.2)$ & $0.92(0.2)$ & $0.94(0.3)^{*}$ \\
Cadence $($ steps/min) & $150.1(42.3)$ & $139.4(39.8)$ & $136.8(39.7)$ \\
RF RMS $(\mu \mathrm{V})$ & $44.4(30.7)$ & $37.9(27.0)$ & $31.3(19.1)^{*}$ \\
BF RMS $(\mu \mathrm{V})$ & $59.8(51.9)$ & $47.1(31.7)$ & $39.7(23.1)^{*}$ \\
TA RMS $(\mu \mathrm{V})$ & $65.6(26.7)$ & $60.4(21.2)$ & $53.5(16.7)^{*}$ \\
GL RMS $(\mu \mathrm{V})$ & $62.9(33.7)$ & $54.0(33.3)$ & $48.7(28.6)^{*}$ \\
Thigh CoI of stance & $0.57(0.08)$ & $0.58(0.07)$ & $0.58(0.08)$ \\
Thigh CoI of swing & $0.59(0.07)$ & $0.59(0.07)$ & $0.58(0.09)$ \\
Leg CoI of stance & $0.57(0.09)$ & $0.58(0.15)$ & $0.57(0.14)$ \\
Leg CoI of swing & $0.46(0.09)$ & $0.47(0.12)$ & $0.48(0.11)$ \\
\hline
\end{tabular}

Data are presented as mean (SD).

RMS: root mean square; RF: rectus femoris; BF: biceps femoris; TA: tibialis anterior; GL: gastrocnemius of lateral head; CoI: coactivation index.

*Significantly different from no cane $(\mathrm{p}<0.05)$. 


\section{DISCUSSION}

The purpose of this study was to investigate the walking parameters and lower limb muscle activity and to clarify the effects of using one or two canes during walking in adults with spastic CP. We found that two canes decreased lower limb muscle activity; however, walking speed also decreased and muscle coactivation was not changed. This suggests that the use of canes decreases the burden on the lower limbs in adults with CP.

Our results show that walking speed with two canes decreased more than without a cane. In a study of stroke patients, those who did not use a cane in daily life had reduced walking speed when using a cane ${ }^{19)}$. Also, it has been reported that the need for attention due to the use of a cane reduces walking speed ${ }^{20}$. In addition, although a cane can generate propulsion and braking forces, these depend on the method of use and the ability of the user ${ }^{5)}$. In this study, eight participants did not use a cane in daily life, as a result, walking speed was reduced by these factors. In contrast, participants of GMFCS III increased their walking speed with two canes. Previous studies of stroke patients also found increased walking speed in participants using canes in their daily lives ${ }^{20}$. For these reasons, after first determining if a cane is necessary, sufficient practice and experience are required to effectively use the cane in CP.

In this study, walking speed was significantly lower with two canes than without a cane; also, stride time was significantly greater without a cane than with two canes. The change of walking parameters in our study is consistent with previous studies in children with $\mathrm{CP}^{8}$ ). Young et al. reported that a more stable gait with a cane increased stride time, and helped to control the movements of CP patients ${ }^{8}$; however, walking parameters were reported to depend on walking speed ${ }^{21)}$. Therefore, it cannot be determined whether the change in strategy or the influence of walking speed affects the walking parameters when walking speed decreases. Meanwhile, stroke patients have increased stride length when utilizing a cane ${ }^{22)}$; however, no change in stride length was observed in CP patients. These results indicated that CP impairs the ability to increase stride while walking ${ }^{23)}$.

For all muscles, muscle activity normalized by the average amplitude was lower when walking with two canes than without a cane. Using a cane has been reported to reduce the burden on the lower limbs as it reduces weight-bearing and vertical reaction force ${ }^{5}$; however, muscle activity is reported to depend on walking speed ${ }^{24)}$. Therefore, it cannot be determined whether the reduced muscle activity is due to walking speed or the use of the cane; although, in the GMFCS III participants, the walking speed was faster and the muscle activity was reduced, so it can be presumed that it was the effect of the canes. Consequently, the use of a cane reduces the burden on the lower limbs of participants with CP in daily life and therapy. In a previous study, one-third of adults with CP reported chronic pain, and more pain in the lower back and lower limbs ${ }^{25}$. Also, overactivity of muscles is reported to be one of the causes of pain ${ }^{26)}$. Further studies are needed to determine whether the use of canes can reduce pain. In addition, although a significant difference was observed with one cane in the previous study ${ }^{8)}$, the muscle activity tended to decrease in this study, but there was no significant difference between the use of no cane and one cane or between the use of one cane and two canes. There are two possible reasons for these. First, it included participants who did not use canes in their daily lives. Second, the participants were adults with CP, and it is expected that their physical function was lower than that of children with $\mathrm{CP}$, suggesting that one cane was not effective enough.

In contrast, the CoI did not change with the use of a cane in any phase even though stability was compensated by using a cane. This suggests that cane use in adults with CP does not affect the CNS and always shows a constant muscle activation pattern. In fact, children with $\mathrm{CP}$ have been reported to have fewer patterns for controlling muscle activity than healthy children ${ }^{27}$. Furthermore, as the participants in this study were adult CP patients, many abnormal movements would have accumulated over the years, and it is conceivable that the movement patterns can be difficult to change. Therefore, it will be necessary to investigate long-term cane use in children with CP.

This study had some limitations. First, because the participants of this study included those who did not use a cane in their daily lives, in experience with cane walking may have influenced the results. Second, because the influence of walking speed could not be excluded, it was difficult to differentiate the influence of walking with a cane or the influence of walking speed; although, the effect of the cane on the participants of GMFCS III was confirmed. Third, because this study was a cross-sectional study, the effects of inexperience and the long-term use of canes cannot be clarified. A longitudinal study should be conducted in the future.

In conclusion, in an adult with CP walking with two canes, the walking speed is reduced, but the lower limb muscle activity is also reduced compared to that without a cane or with one cane. It was suggested that the burden to lower limb muscles was reduced. However, the rate of agonist and antagonist muscle coactivation did not change, suggesting that the movement pattern did not change. Therefore, this study helps to consider the use of the cane in adult CP.

\section{Funding and Conflict of interest}

This work did not receive any specific grant from funding agencies in the public, commercial, or not-for-profit sectors, and the authors have no conflicts of interest to declare. 


\section{REFERENCES}

1) Vargus-Adams JN, Martin LK, Maignan SH, et al.: The GMFM, PEDI, and CP-QOL and perspectives on functioning from children with CP, parents, and medical professionals. J Pediatr Rehabil Med, 2011, 4: 3-12. [Medline] [CrossRef]

2) Jaspers E, Verhaegen A, Geens F, et al.: Lower limb functioning and its impact on quality of life in ambulatory children with cerebral palsy. Eur J Paediatr Neurol, 2013, 17: 561-567. [Medline] [CrossRef]

3) Morgan P, McGinley J: Gait function and decline in adults with cerebral palsy: a systematic review. Disabil Rehabil, 2014, 36: 1-9. [Medline] [CrossRef]

4) Logan L, Byers-Hinkley K, Ciccone CD: Anterior versus posterior walkers: a gait analysis study. Dev Med Child Neurol, 1990, 32: 1044-1048. [Medline] [CrossRef]

5) Bateni H, Maki BE: Assistive devices for balance and mobility: benefits, demands, and adverse consequences. Arch Phys Med Rehabil, 2005, 86: 134-145. [Medline] [CrossRef]

6) Tagawa Y, Shiba N, Matsuo S, et al.: Analysis of human abnormal walking using a multi-body model: joint models for abnormal walking and walking aids to reduce compensatory action. J Biomech, 2000, 33: 1405-1414. [Medline] [CrossRef]

7) Jeka JJ, Easton RD, Bentzen BL, et al.: Haptic cues for orientation and postural control in sighted and blind individuals. Percept Psychophys, 1996, 58: 409-423. [Medline] [CrossRef]

8) Yeung EH, Chow DH, Su IY: Kinematic and electromyographic studies on unaided, unilateral and bilateral crutch walking in adolescents with spastic diplegia. Prosthet Orthot Int, 2012, 36: 63-70. [Medline] [CrossRef]

9) Damiano DL, Martellotta TL, Sullivan DJ, et al.: Muscle force production and functional performance in spastic cerebral palsy: relationship of cocontraction. Arch Phys Med Rehabil, 2000, 81: 895-900. [Medline] [CrossRef]

10) Fowler EG, Staudt LA, Greenberg MB, et al.: Selective Control Assessment of the Lower Extremity (SCALE): development, validation, and interrater reliability of a clinical tool for patients with cerebral palsy. Dev Med Child Neurol, 2009, 51: 607-614. [Medline] [CrossRef]

11) Tomita H, Fukaya Y, Takagi Y, et al.: Effects of severity of gross motor disability on anticipatory postural adjustments while standing in individuals with bilateral spastic cerebral palsy. Res Dev Disabil, 2016, 57: 92-101. [Medline] [CrossRef]

12) Woollacott MH, Shumway-Cook A: Postural dysfunction during standing and walking in children with cerebral palsy: what are the underlying problems and what new therapies might improve balance? Neural Plast, 2005, 12: 211-219, discussion 263-272. [Medline] [CrossRef]

13) Oshita K, Yano S: Effect and immediate after-effect of lightly gripping the cane on postural sway. J Physiol Anthropol, 2016, 35: 14. [Medline] [CrossRef]

14) Kitatani R, Ohata K, Sakuma K, et al.: Ankle muscle coactivation during gait is decreased immediately after anterior weight shift practice in adults after stroke. Gait Posture, 2016, 45: 35-40. [Medline] [CrossRef]

15) Tucker MG, Kavanagh JJ, Barrett RS, et al.: Age-related differences in postural reaction time and coordination during voluntary sway movements. Hum Mov Sci, 2008, 27: 728-737. [Medline] [CrossRef]

16) Rueterbories J, Spaich EG, Larsen B, et al.: Methods for gait event detection and analysis in ambulatory systems. Med Eng Phys, 2010, 32: 545-552. [Medline] [CrossRef]

17) Rosa MC, Marques A, Demain S, et al.: Methodologies to assess muscle co-contraction during gait in people with neurological impairment - a systematic literature review. J Electromyogr Kinesiol, 2014, 24: 179-191. [Medline] [CrossRef]

18) Chow JW, Yablon SA, Stokic DS: Coactivation of ankle muscles during stance phase of gait in patients with lower limb hypertonia after acquired brain injury. Clin Neurophysiol, 2012, 123: 1599-1605. [Medline] [CrossRef]

19) Ijmker T, Houdijk H, Lamoth CJ, et al.: Effect of balance support on the energy cost of walking after stroke. Arch Phys Med Rehabil, 2013, 94: 2255-2261. [Medline] [CrossRef]

20) Suzuki T, Ogahara K, Higashi T, et al.: The effect of cane use on attentional demands during walking. J Mot Behav, 2019, 51: 19-24. [Medline] [CrossRef]

21) Paróczai R, Kocsis L: Analysis of human walking and running parameters as a function of speed. Technol Health Care, 2006, 14: 251-260. [Medline] [CrossRef]

22) Kuan TS, Tsou JY, Su FC: Hemiplegic gait of stroke patients: the effect of using a cane. Arch Phys Med Rehabil, 1999, 80: 777-784. [Medline] [CrossRef]

23) Abel MF, Damiano DL: Strategies for increasing walking speed in diplegic cerebral palsy. J Pediatr Orthop, 1996, 16: 753-758. [Medline] [CrossRef]

24) Sousa AS, Tavares JM: Effect of gait speed on muscle activity patterns and magnitude during stance. Mot Contr, 2012, 16: 480-492. [Medline] [CrossRef]

25) Jahnsen R, Villien L, Aamodt G, et al:: Musculoskeletal pain in adults with cerebral palsy compared with the general population. J Rehabil Med, 2004, 36: 78-84. [Medline] [CrossRef]

26) Broseta J, García-March G, Sánchez-Ledesma MJ, et al.: Chronic intrathecal baclofen administration in severe spasticity. Stereotact Funct Neurosurg, 1990, 54-55: 147-153. [Medline] [CrossRef]

27) Steele KM, Rozumalski A, Schwartz MH: Muscle synergies and complexity of neuromuscular control during gait in cerebral palsy. Dev Med Child Neurol, 2015, 57: 1176-1182. [Medline] [CrossRef] 